\title{
Digital Twin - A Key Technology driver in Industry 4.0
}

\author{
Vijay Anant Athavale ${ }^{1 *}$ and Ameya Athavale ${ }^{2}$ \\ ${ }^{1}$ Panipat Institute of Engineering and Technology, India \\ ${ }^{2}$ Shri Govindram Seksaria Institute of Technology \& Science, India
}

Submission: July 06, 2021; Published: August 04, 2021

*Corresponding author: Vijay Anant Athavale, Panipat Institute of Engineering and Technology, Samalkha, Panipat, Haryana, India

\begin{abstract}
Technological innovations are a synthesis of the past with the economical and functional possibilities of the future. Production is continually improving because of technological advancements and innovations, and this process has gone through three key revolutions. The technologies that underpin these revolutions have assumed the role of catalyst in the industrial process. Whenever, technical advancement has increased, it has resulted in technological pressures in the production area, resulting in industrial revolutions. Cyber-physical systems, cloud computing, internet of things (IoT), autonomous systems, big data, augmented reality / virtual reality, and 3D printing technologies are all contributing in industrial revolution 4.0. Each of these technologies has evolved independently and has diverse application areas, but when utilized together, they were able to change manufacturing from a traditional structure to a smarter structure. Physical factories that were first digitized and subsequently virtualized became "smart factories" as a result of this synergy. The Digital Twin has evolved into a key technology for achieving synergy through the use of the technologies mentioned in the implementation of smart factories, starting at the concept stage of a physical product and based on the concept of obtaining a virtual copy with real-time data throughout the product's life cycle.
\end{abstract}

Keywords: Digital twin; Industry 4.0; Smart factory; IoT; Cyber-physical system

\section{Introduction}

A Digital Twin is a real-time digital profile of a physical object's or process's past and present behavior that aids business performance and is based on large, cumulative, real-time and real-world data. Digital twin technology is considered as a key technology for the realization of cyber-physical systems, which is the most important component of Industry 4.0 [1]. The basic idea is to create a stand-alone digital information structure about a physical system.

This digital information is the "twin" of the information embedded in the physical system and is linked to this physical system throughout its lifecycle. The digital twin technology, which emerged as a result of NASA's mapping technology, was first introduced in 2002 at the Product Lifecycle Management (PLM) center. In his presentation to the industry at the University of Michigan for its creation was used by Michael Grieves [2] and its conceptual model was presented in 2006 [3]. The conceptual model emerged from the need to bring together all the data and information of a physical asset for a higher level analysis for a mission within NASA's Apollo program.
Two identical spacecraft were built to reflect the conditions of the spacecraft. The spacecraft which remained on earth was called a twin. The twin was widely used for training during flight preparation. During the flight mission, the earth-based model was used to reflect the flight conditions of the available flight data as precisely as possible and thus assist orbiting astronauts in critical situations, and also used to simulate alternatives. In this sense, any prototype used to simulate real-time behavior and reflect real operating conditions can be seen as twin. Grieves' conceptual model was named as the "Information Reflection Model" [3], later referred to as the "Digital Twin" in the NASA Technology Roadmap in 2010 [4] and continued to be used as such.

The digital twin concept aims to digitize products, product development processes and entire production. In this context, when the concept in Figure 1 is examined, it is seen that a threestage mechanism is being used in the transition from the physical environment to the digital environment.

Over the digital master data, which includes the original and physical product features, a digital shadow is created that includes 
operational status data, process data, facility and infrastructure data and all detailed data of the product, and finally, digital twin is produced by integrating these two main layers. Although the ideas about creating a digital copy of a product or process are not new, the work carried out to obtain a digital copy that is closest to the truth has been continuous since the use of computers in businesses.

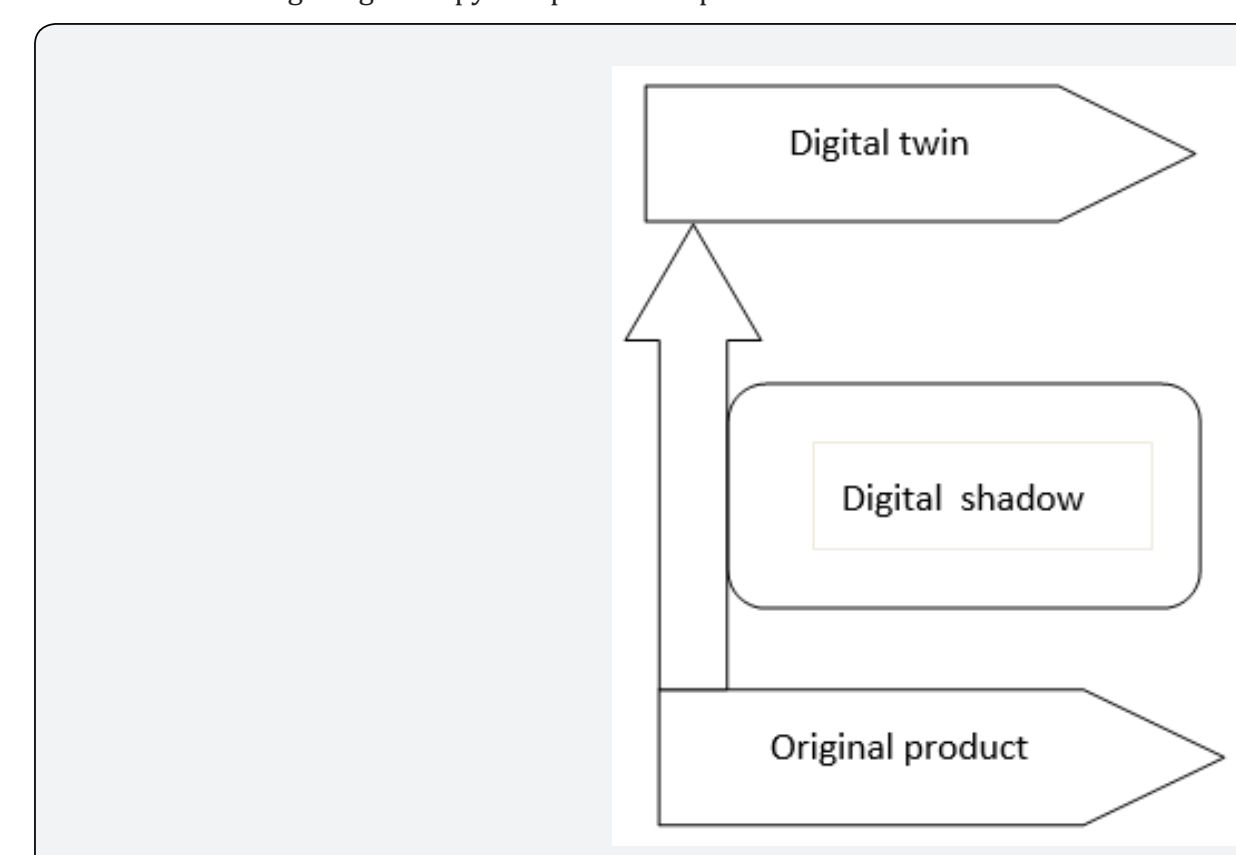

Figure 1: Conceptual model of Digital Twin.

Due to computer-aided production and design technologies (CAD / CAM), the product can be physically modeled while it is still in the idea stage, while the effects of the factors affecting the product on the product can be tested thanks to simulation programs, virtual reality (VR) and remote applications can be used to see the results more realistically.

Augmented reality (AR) technologies were used to perform the controls. However, digital twin technology can be used to simultaneously monitor and control the digital copies, and moreover, with the use of real-time and instant environmental data of the products, it has become not only a digital copy, but also an important building block on the way to the smart factory, with its features of being a self-managing product by enabling understanding, learning and reasoning.

The application of the digital twin concept and similar applications that lead to increased productivity have also been seen in the telecommunication sector and the health sector. Although, the digital twin that make 4.0 applicable for businesses, promise to provide a lot of economic and time benefits for businesses. The complexity and implementation costs of digital twin vary according to their intended use. The advantages brought by their size have not yet been fully demonstrated. The results of using digital twin for simple, few parts and low test costs, which are used in the production and follow-up of multi-part and complex products, which mostly require high security standards in business applications, and which provide great benefits to business, are not yet sufficient.

\section{Conclusion}

Digital twin is still very open to development and understanding, both because we are just at the beginning of digital twin generation technologies and because we don't have benchmark data on success in business application results in different industries and different sizes.

\section{References}

1. Zhuang C, Liu J, Xiong H (2018) Digital twin-based smart production management and control framework for the complex product assembly shop-floor. Int J Adv Manuf Technol 96: 1149-1163.

2. Singh M, Fuenmayor E, Hinchy EP, Qiao Y, Murray N, et al. (2021) Digital Twin: Origin to Future. Applied System Innovation. 4(2): 36.

3. Grieves M (2006) Product lifecycle management: driving the next generation of lean thinking. McGraw-Hill Education, New York, USA.

4. National Aeronautics and Space Administration (NASA) (2010) Technology area 12: materials, structures, mechanical systems and manufacturing road map. USA. 
Your next submission with Juniper Publishers will reach you the below assets

- Quality Editorial service

- Swift Peer Review

- Reprints availability

- E-prints Service

- Manuscript Podcast for convenient understanding

- Global attainment for your research

- Manuscript accessibility in different formats ( Pdf, E-pub, Full Text, Audio)

- Unceasing customer service

Track the below URL for one-step submission https://juniperpublishers.com/online-submission.php 